\title{
MISERIA DE LA ECONOMÍA \\ La controversia sobre la asistencia social y hospitalaria en el siglo XVI
}

\author{
Mariano Monge JuÁrez / Cristina López Osuna \\ Universidad de Alicante
}

«...los que sólo miran a los ricos despreciando a los pobres, hacen lo mismo que si un mendigo juzgase que no se debía socorrer con la mendicidad las manos y los pies, porque distan mucho del corazón; lo cual, así como no se haría con grave daño de todo el hombre, así en la república no se desprecian los más débiles sin peligro de los poderosos»

Luis Vives,

De suvbentione pauperum, 1526

\section{RESUMEN}

El artículo es una reflexión sobre el significado del enfrentamiento de los dos grandes modos de entender la asistencia social hospitalaria durante el siglo XVI: por una parte, los defensores de la asistencia como limosna y por otra los humanistas, partidarios de las reformas sociales y la educación de las clases marginadas. La hipótesis de la que parte el trabajo es que a raiz del desarrollo de las prácticas capitalistas la miseria

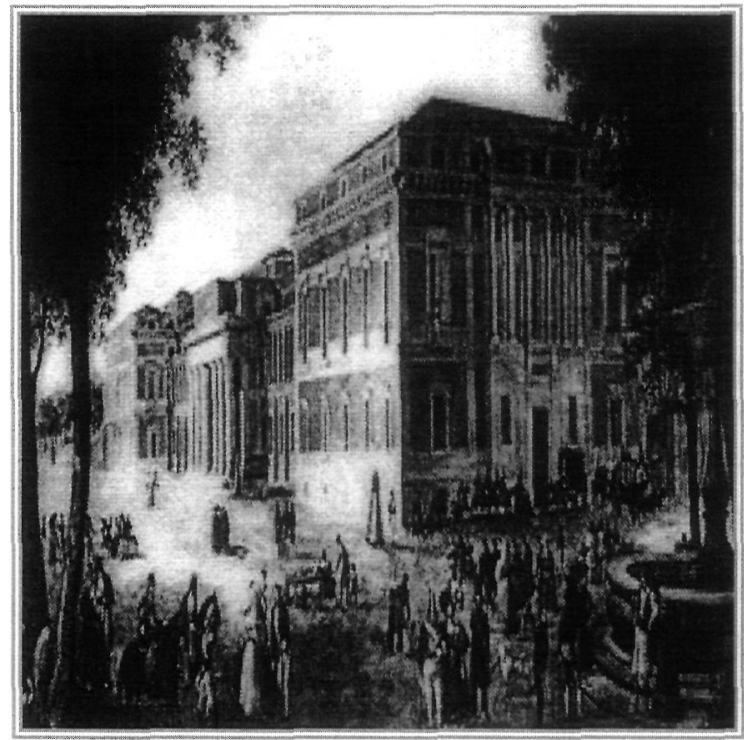
comienza a ser una amenaza para el Estado, por ello las oligarquías de poder se ven obligadas a construir una política de asistencia sanitaria enfrentada con la Iglesia, que tradicionalmente había controlado los hospitales.

El debate sobre el concepto teórico de la asistencia social hopitalaria iniciado durante el siglo XVI se proyecta en la actualidad en una situación provocada por la crisis del estado de bienestar. Asistimos a una nueva controversia sobre quién tiene que administrar la asistencia hopitalaria, el Estado o la «Iniciativa Privada».

\section{POVERTY WITHIN ECONOMY: A controversial discussion on social and hospital attention in the 16th $c$.}

\begin{abstract}
The present article is a reflection on the opposition of the two main ways of understanding social and hospital care during the 16th century. On the one hand, there were those who argued that caring it should be a sort of religious charity. On the other hand, there were the humanists who stood for social reforms and education for marginalized sectors. The hypothesis presented in this article comes from the following consideration: «Whenever there is a development of capitalist performance, poverty begins to be a threat to the state, thus power oligarchies are obliged to build a policy of sanitary care opposite to the care offered by the Church who traditionally has had the control of the hospitals».

The debate about the theoretical concept of the social-hospital-care, started during the 16th century surfeces today in the form of the welfare crisis. At present we face a new controversial debate on who should deal with the administration of hospital care; either the government or the private sector.
\end{abstract}




\section{INTRODUCCIÓN}

Indisolublemente unida a la pobreza ha estado siempre la enfermedad, así cuando hablemos de pobres, y marginados sociales en general, estaremos hablando también de enfermos, tanto físicos como mentales. Es más, como veremos más adelante, la enfermedad y la falta de higiene, históricamente, han sido el principal argumento que han exhibido los mendigos. Desgraciadamente, la insatisfacción de las necesidades más básicas para millones de seres humanos ha sido siempre una oculta y siniestra característica de nuestras sociedades.

La miseria, en todas sus manifestaciones, es el fenómeno más constante de la civilización humana, y sobre todo de la sociedad que albergó las primeras prácticas capitalistas, llegados a este punto podríamos partir de la siguiente hipótesis: la pobreza está ligada íntimamente al sistema económico: para Malthus, la miseria es el precio inevitable del desarrollo, en cambio para Marx es el ejemplo más evidente de los errores y desequilibrios del capitalismo, es decir, la miseria es la consecuencia de la injusta distribución de los recursos, no de su insuficiencia.

Para el fundador del socialismo científico había tres clases de pobres: los aptos para el trabajo, los menos aptos y los no aptos. El filósofo y economista de Treveris pensaba que la miseria es « el refugio de los inválidos del ejército obrero activo y el peso muerto del ejército industrial de reserva» (Geremek, 1989: 249). Así pues, el pauperismo ha sido una condición indispensable para el desarrollo de la producción capitalista, cuya consecuencia inmediata es el desequilibrio más o menos acentuado entre los grupos que forman la sociedad: «...la acumulación de riqueza en uno de los polos es (...) al mismo tiempo acumulación de miseria, tormento de trabajo, esclavitud, ignorancia, embrutecimiento y degradación moral en el polo opuesto...» (Geremek, 1989: 249). Si echamos un simple vistazo a la historia desde el descubrimiento de América y en especial a los últimos ciento cincuenta años parece demostrada la hipótesis de Marx.

Hasta tal punto se observa la relación causaefecto entre miseria y sistema económico* que debería de ser un factor más importante en los índices de desarrollo, -mucho más real que la producción de acero, o la renta per capita-. Decía Gianmaria Ortes en 1774: «la riqueza de una nación corresponde a su población y a su miseria. La laboriosidad de algunos es la causa del ocio de otros. Los pobres y los ociosos son un producto inevitable de los ricos» (Geremek, 1989: 248).

En cambio, otro análisis de la pobreza, el del pensamiento económico y social conservador del siglo XIX, considera la miseria como «una enfermedad vergonzante» consecuencia directa del vicio, la holgazanería y la propia incapacidad de los grupos afectados. Esta ideología se ha mantenido durante el siglo XX, sobre todo en Gran Bretaña y Estados Unidos, donde el determinismo biológico ha gozado de más éxito hasta el punto de considerar la pobreza una condición innata, y por tanto hereditaria, es decir, la miseria es entendida como un hecho natural, consecuencia de la propia inutilidad o inferioridad de algunos seres humanos. Se trataría de un racismo social emparentado con una interpretación errónea de la selección de las especies (darwinismo social) que situaría a los ricos en el grupo mejor dotado y a los marginados, mendigos o desempleados en el vagón de los tontos (Lewontin et al., 1996: 82-156).

Los planteamientos en el siglo XX son mucho más complejos: J. K. Galbraith en La sociedad opulenta afronta el problema con más optimismo, quizá demasiado; la pobreza ya no es una calamidad de las masas, sólo se trata de una circustancia pasajera (Galbraith, 1992: 269-278). Lástima que aquellas palabras del economista británico no pasaran de ser un sonrosado sueño de los felices años cincuenta.

\footnotetext{
* Toda la teoría económica de Marx pretende demostrar que para el desarrollo del capitalismo es condición indispensable la depresión económica de un sector amplimente mayoritario de la sociedad: «Llevado del interés por la llamada riqueza nacional, se echa a buscar los medios más eficaces para producir la pobreza popular» (K. Marx, El Capital: $1: 650)$.
} 
El problema de la simple subsitencia física de millones de personas en el mundo sigue sin solución hoy mismo.

Durante siglos de desarrollo, las sociedades humanas han ido generando marginados, tantos como para ser capaces de crear una cultura al otro lado, una sociedad excluída del mundo en el «subsuelo de la economía», lo que M. Harrington ha llamado «altera civitas in urbe» (Geremek, 1989: 13).

Desde que surgieran las primeras prácticas capitalistas tras el descubrimiento de la montaña de oro americano, hasta el sutil desarrollo económico del inicio del siglo XXI en que vivimos, el oscuro protagonista de la sociedad ha sido la miseria. En este artículo vamos a intentar reproducir cómo se intentó solucionar el problema de la pobreza durante el siglo XVI en España, momento en que comienza el desarrollo de la asistencia social.

\section{ASISTENCIA HOSPITALARIA Y RELIGIÓN}

Para un mundo dominado por las religiones mistéricas, la pobreza es nada menos que un «valor edificante», no obstante, la crisis económica e ideológica que se produjo en el tránsito de la Edad Media al Renacimiento hace que en todo Occidente la Iglesia, tanto católica como protestante, lance las primeras políticas asistenciales. La idealización de la pobreza sufre graves ataques, sobre todo desde la Reforma. Se inicia pues una de las controversias más interesantes y desconocidas en Europa.

H. Pirenne piensa que la característica principal del protestantismo es la tendencia laicista de la asistencia, y distingue tres corrientes teóricas para 1525: erasmista, puritana y capitalista (Pirenne, 1927: III: 290).

En España el debate no es menos interesante: la gran influencia del erasmismo, sobre todo en el primer cuarto del siglo XVI, definirá la política asitencial.

Durante toda la Edad Media, la Biblia había regido el destino de hombres y mujeres. Un libro de leyes morales para «bellatores», «oratores» y campesinos, cuya lectura era reservada sólo para unos cuantos que gozaban del privilegio de interpretar un mundo de puertas cerradas en el que cada estamen- to tenía su función, porque así lo había decidido el cielo. Nada se podía hacer, el hombre no era dueño de su propio destino, sino que estaba en manos de un Dios omnipotente y juzgador. En esta sociedad no cabe una política asistencial muy desarrollada, primero porque ser pobre es una virtud cristiana y un hecho necesario para el perfecto funcionamiento de todo un sistema teocrático; y segundo porque todavía el pauperismo no constituye una verdadera amenaza para ese sagrado equilibrio de la sociedad.

No obstante, durante la Edad Media hubo momentos de grave hostilidad junto a un lento desarrollo de la política asistencial, cuya base era el mensaje social del Evangelio. Un buen ejemplo de esto lo encontramos en la Vida de San Eulogio: «Dios debería haber dado la riqueza a todos los hombres, pero ha querido que haya pobres para que los ricos tuviesen ocasión de redimir sus pecados» (Geremek, 1989: 28)

Hasta llegar al siglo XVI el concepto de la pobreza experimentará una lenta evolución. En el siglo XI parece que la definición de pobreza estaba vinculada a la contraposición entre potens y pauper. Pero en el siglo XII y XIII tienen lugar importantes cambios en el sistema económico europeo y la miseria va adquirendo un sentido más pecuniario en un momento de expansión del comercio. Es entonces cuando se plantean los primeros planes de asistencia más comprometidos. La Iglesia sólo tolerará la pobreza individual, silenciosa y humilde, y condenará la pobreza organizada en un grupo social, que como hemos dicho antes puede suscitar una amenaza. Es pues, el momento de clasificar la miseria en dos grandes grupos, como lo hace Cerhoch de Reichasberg que diferencia a los «pauperes cum Petro» -pobres como Pedro- de los «pauperes cum Lazaro» -pobres como Lázaro-, es decir, los primeros serían los pobres por seguir a Cristo, -los religiosos-, y los segundos los pobres por necesidad (Geremek, 1989: 33). Por otra parte, Tomás de Aquino y Guido de Baysio lanzan las primeras críticas a la caridad, que habría de ser racional para alcanzar el valor de la virtuosidad porque se incorpora el elemento de la mezquindad a ciertas formas de 
pobreza, por ello hay que distinguir muy bien a quién se le da la limosna.

Es importante llamar la atención sobre la magnitud de la limosna en las sociedades dominadas por las religiones mistéricas. La limosna forma parte de la liturgia funeraria de los nobles o comerciantes adinerados; las órdenes monásticas organizan remesas de limosnas a la muerte de cada miembro de la comunidad y también durante los viajes de los reyes.

Todo esto contribuyó a la multiplicación del oficio de pobre, pero sobre todo debido a periódicas crisis de subsitencia, pestes, guerras del los siglos XIV y XV, éxodo rural de los primeros momentos del Renacimiento, y en especial, la proliferación de las primeras prácticas capitalistas que incidieron en agravar las diferencias sociales por las que millares de europeos se redujeron a la miseria. Las ciudades se van llenando progresivamente de vagabundos harapientos. Los acontecimientos se precipitarán, la armonía medieval se ha roto; la política social tiene que sufrir un giro importante igual que la moral y la ética.

\section{LA NUEVA ÉTICA Y EL CAMBIO EN EL PENSAMIENTO SOCIAL Y ECONÓMICO}

La velocidad de la historia se acelera. Colón llega a las Indias Occidentales y la economía española y europea se pone patas arriba en apenas treinta años. ¿Por qué se plantea en aquellos años -hacia 1525 - con tanto interés la asistencia social?; nosotros pensamos que dos razones pueden dar la respuesta: en primer lugar los pobres se habían convertido en una amenaza real para el orden social, y en segundo lugar el cambio de las mentalidades hace posible la transfusión de la virtuosidad desde la visión estática medieval hacia el trabajo, sobre todo tras la propagación de la Reforma.

Pero la historiografía tradicional presenta a España como un país de hidalgos que desprecian el trabajo manual, concepto alimentado por la literatura picaresca de El Lazarillo de Tormes o El Buscón. No obstante, nosotros pensamos que la sociedad española del siglo XVI participa de esta gran revolución de las mentalidades que supone la Re- forma. La primera manifestación de envergadura es De subventione pauperum, publicado en 1526 por el humanista valenciano Luis Vives. Y lo importante no será su publicación, sino sus consecuencias, pues la obra inaugurará la polémica sobre la asistencia social, además, seis años más tarde, un Edicto Imperial establece una serie de reglas para la política asistencial.

Pero, ¿cómo se explica la aparición de un debate sobre el qué hacer con los indigentes? Los primeros años del siglo XVI habían sido de malas cosechas $(1504,1508,1513)$, Europa sufría una crisis generalizada. La miseria es una plaga demoniaca para las ciudades, en las que no caben más vagabundos y ladrones. Los mendigos -dice Jean Delumeau- se han convertido en agentes del diablo (Delumeau, 1989: 631-637)

España no está fuera de todo este clima, y como decíamos, las medidas no se hacen esperar; en 1523, las Cortes de Valladolid deciden que los pobres solamente tendrán derecho a pedir limosna en su lugar de origen. En 1525, las Cortes de Toledo incluso prohiben mendigar sin un permiso específico, posteriormente, las Cortes de Madrid en 1528, y las de 1534 , toman medidas similares.

La agitación social se generaliza en Europa, las revueltas campesinas de la década de los veinte en España coinciden con las de Inglaterra, Francia, Alemania y Paises Bajos, y el miedo a la sedición de los desposeidos se propaga como un gas venenoso entre la aristocracia. Para el Estado, la vía asitencial se presenta como la única solución antes de que sea demasiado tarde. M. Geremek recoge una infinidad de ejmplos en toda Europa: en París los pobres quedarán bajo la tutela del Parlamento. Se observa pues una marcada laicización de la organización hospitalaria.

En España la influencia de Erasmo de Rotterdam a través de Luis Vives inspira la política asistencial. En 1540, Carlos I ordena que en cada ciudad haya un sólo hospital y que se prohiba la mendicidad por las calles. El Estado Moderno, cada vez más poderoso, en un proceso de construcción y autoafirmación, pretende controlar la asistencia social, y desvincular a los religiosos de estas tareas, 
pero las nuevas ideas reformistas chocan directamente con la Iglesia que no están dispuestos a ceder una importante parcela de poder que les hace controlar una parte de la sociedad. Por tanto, la controversia no significa solamente lucha entre dos mentalidades, la renacentitas y la medievalista, como ven algunos autores, sino que va mucho más allá, se trata del enfrentamiento entre el Estado y la Iglesia por el control de un sector de la sociedad, tan importante que bien podía ser utilizado como arma arrojadiza. En realidad, el problema no es la asitencia, sino el control de la asitencia, no es una cuestion moral, es una cuestión de estrategia económico-política.

Pero volvamos a incidir sobre la trascendencia del giro de la mentalidad. El humanismo significa la llegada de una nueva jerarquía de valores. Max Weber considera la ética protestante como el germen del espíritu capitalista, hasta el punto de identificarla con una «filosofía de la avaricia»(Weber, 1992: 43). M. Lutero había creado la idea del hombre honrado, cuya única misión es el trabajo, un hombre con un concepto de la vida para no vivirla. J. Fugger resume muy bien el nuevo espíritu: «ganar todo cuanto se pueda»(Weber, 1992: 45). La vida es producción. Incluso un artista, como el genial arquitecto del renacimiento italiano, Leon Battista Alberti había afirmado en su obra Della Famiglia que el tiempo era dinero, »pecunia nervus rerum» en frase muy similar a la de Richelieu. Si el trabajo es el nuevo becerro de oro, los vagabundos, holgazanes o pobres tenían poco lugar en esta sociedad, y España no queda al margen de todo esto.

En cualquier caso, no es posible hablar de una revolución de la justicia social, más bien todo lo contrario. Lutero consideraba la profesión de cada uno como «la misión impuesta por Dios al hombre» (Weber, 1992: 101). En realidad, se sigue divinizando el orden social y el poder de las oligarquias. El trabajo derivaba del «amor al prójimo para servir la gloria de Dios» ( Weber, 1992: 135). También para Calvino el trabajo se hará «in maiorem Dei gloriam» (Weber, 1992: 131). Según los reformadores, el trabajo es una condición indispensable para la salvación del alma, incluso se «inculcó la ne- cesidad de recurrir al trabajo profesional incesante, único modo de ahuyentar la duda religiosa y de obtener la seguridad del propio estado de gracia» (Weber, 1992: 138).

El trabajo duro será un medio ascético: «Si Dios os muestra un camino que va a proporcionar más riqueza que siguiendo un camino distinto (sin perjuicio de vuestra alma o de las otras) y lo rechazais para seguir el que os enriquece menos, poneis obstáculos a uno de los fines de vuestra vocación y os negais a ser administradores de Dios y a aceptar sus dones para utilizarlos en su servicio cuando Él os lo exige. Podeis trabajar para ser ricos, no para poner luego vuestra riqueza al servicio de vuestra sensualidad y vuestros pecados, sino para honrar con ella a Dios» (Weber, 1992: 216) La holganza, es pues, pecado.

Detrás de esta teología que diviniza el trabajo está la lógica capitalismo: en definitiva el tiempo es igual a dinero. La reforma luterana supone la base rudimentaria para la construcción de la economía clásica de A. Smith, D. Ricardo y K. Marx.

\section{TRABAJO Y REPRESIÓN}

Como ya hemos venido a decir antes, los nuevos agentes del diablo, los pobres y marginados, serán un elemento perturbador para el Estado Moderno (Delumeau, 1989: 631), luego, llegados a este punto, podemos concluir que la satisfacción de las necesidades de los indigentes no era un fin, sino más bien, un medio susceptible de ser utilizado por las oligarquías de poder.

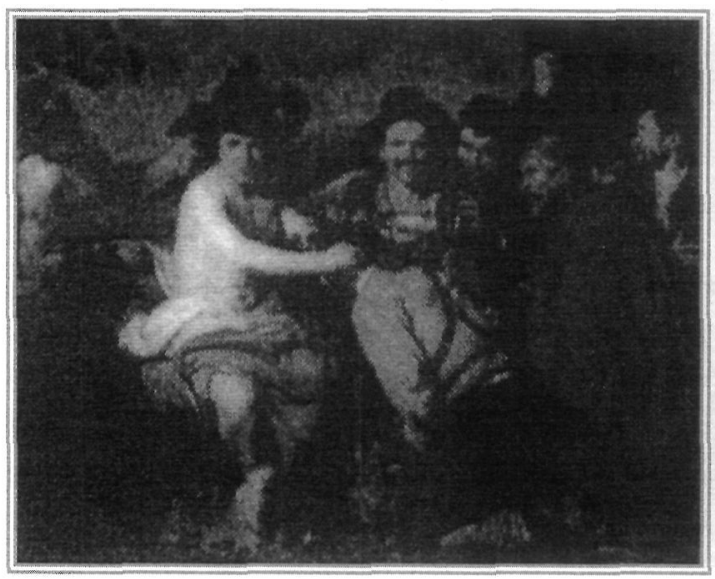


$\mathrm{Y}$ es que desde los desórdenes producidos en centroeuropa, causados por los hussitas, se respiraba un aire de inestabilidad social. El espíritu taborita continuó latiendo entre las masas populares, todo esto despertó el miedo entre los poderosos. Además, los mendigos y vagabundos ¿no eran acaso sembradores de pestes, inmoralidad y desorden?; este temor, más el concepto de trabajo igual a virtud antes aludido, explican las medidas represivas contra la indigencia que se adoptaron en algunos lugares. En muchas ocasiones los mendigos fueron recluídos y obligados a trabajar bajo amenaza de tortura o pena de muerte, por ejemplo, en Amsterdam «si un pobre se negaba a trabajar era encerrado en un sótano, que poco a poco se llenaba de agua. El recluso disponía de una bomba, y para salvarse de morir ahogado debía bombear sin descanso el agua del local» (Geremek, 1989: 236). Este método se consideraba eficaz para vencer la pereza y adquirir la costumbre de trabajar. En España, las circunstancias nunca llegaron a ser tan extremas, probablemente por la pervivencia, en algunos sectores, de la mentalidad medieval, pero tambien gracias a la influencia de Erasmo de Rotterdam, defensor de la pedagogía y contrario a la represión.

\section{ESPAÑA Y LA ASISTENCIA SOCIAL: LOS HOPITALES}

Se puede decir que el erasmismo es la fuente teórica de la que se nutrió parte de la política asitencial en España, sobre todo en los primeros treinta o cuarenta años del siglo XVI.

En los manuales de Historia de España sobre el Renacimiento no se suele hablar de la importancia que llegó tener la asistencia hospitalaria, aunque en realidad fue uno de los factores más relevantes de la política imperial.

Quizá sea una paradoja, pero muchos hospitales se convirtieron en motivo de orgullo y ostentación para algunas ciudades. Estos hopitales canalizaban la asitencia social a las clases más deprimidas, cuya administración podía correr a cargo de un particular, una orden religiosa, el municipio o de la iniciativa real. Además de las asignaciones ordinarias que eran casi siempre insuficientes, la manutención se completaba con las limosnas que reunían los propios mendigos o las donaciones de particulares. Si era dirigido por religiosos, la subvención podía proceder del obispado, de las aportaciones de los indigentes y de las limosnas que los religiosos aportaban, ya que muchos de estos eran mendicantes y salían a pedir para sus enfermos o pobres.

Algunos hospitales se mantenían, en parte, gracias a los ingresos que aportaban los propietarios de los burdeles, como ocurría en Sevilla (Perry, 1993: 146). Aunque no sabemos si ésta era una práctica generalizada en España, pues el patrocinio más frecuente era el particular. Por ejemplo, Catalina de Ribera (Perry, 1993: 32-33) funda un hospital para mujeres mendicantes en Sevilla a mediados del siglo XVI. Estas obras de caridad abundaban, sobre todo a la muerte de nobles en cuyo testamento dejan una parte de su fortuna al socorro de los más necesitados.

También los gremios asumieron una no despreciable función, como el de tejedores de Seda de Sevilla que subvencionó el hospital de San Onofre con el que colaboró con dinero y trabajo personal ( Perry, 1993: 152).

Según Elisabeth Perry, algunos hospitales tendían a ubicarse fuera de las murallas, aunque con el crecimiento se incluyeran en el plano urbano, en cambio, en otras ciudades los hopitales se encontraba en lugares privilegiados por ser elementos simbólicos y prestigiosos, como el de Santiago de Compostela.

Estas instituciones benéficas solían atender a todos los necesitados, al margen de su raza o religión, aunque esta tolerancia se rompía en algunas épocas conflictivas, por ejemplo, a partir de los levantamientos moriscos la asistencia se hizo más selectiva: en algunos lugares sólo se tomaban pobres cristianos viejos.

\section{DATOS CUANTITATIVOS SOBRE LA POBREZA}

Durante el siglo XVI el fortalecimiento de la administración estatal en España y en otros países del resto de Europa hizo que se llevaran a cabo los primeros censos de población relativamente fiables. 
De todos modos, tenemos estas cifras no pueden tomarse como extrictamente ciertas por el escaso desarrollo de los métodos cuantitativos en aquellos momentos, y más importante, por tratarse de la población marginada, todavía más dificil de controlar por razones obvias; además, la población era bastante recelosa a los censos por estar relacionados éstos con la recaudación de impuestos. También hay que añadir que las crisis periódicas que se sufrían disparaban temporalmente la miseria. Por estas razones, hay que tener en cuenta el valor aproximativo de los datos: J. Delumeau cifra el porcentaje de pobres sobre la población general europea en un $10 \%$. Aunque las investigaciones al respecto de C. M. Cipolla ofrecen diferentes resutados, para el economista italiano los indigentes podían llegar hasta el $20 \%$ de la población urbana (Cipolla, 1990: 25).

Otro factor importante es la heterogeneidad de la distribución geográfica de la pobreza, sobre todo en España, que probablemente nunca bajó del $10 \%$ de la población total. Lo que sí parece claro es que las grandes bolsas de indigencia se encontraron sin duda en las ciudades.

Según los censos ordenados por la administración de Felipe II, B. Bennassar piensa que los pobres, tanto sedentarios como vagabundos alcanzaban más del $10 \%$ en todo el reino. Estos datos nos han permitido elaborar un cuadro en el que se puede observar la gran diferencia de unas cifras a otras teniendo en cuenta la región en que se encuentra la ciudad:

Datos en torno a 1590 (B. Benassar, 1978: 129)

Valladolid $9,5 \%$

Segovia .................

$10 \%$

Tudela de Duero ............

$14 \%$

Alcalá de Henares

$10 \%$

Ciudad Real.

$16 \%$

Jaen $19,5 \%$
El número de indigentes oscilaba, pero seguió un ritmo ascendente durante todo el siglo XVI y XVII. Por ejemplo, durante la crisis de 1575-77 parece que el número de pobres se multiplicó por tres. Los lugares de mayor concentración de miseria fueron Leon, Oviedo, Valladolidd, Salamanca, Sevilla, Málaga, Granada y Zamora.

También se conocen movimientos migratorios de vagabundos que podrían ir desde la vertiente cantábrica hasta la meseta central. En definitiva, los pobres oscilaban según épocas y zonas. Extremadura era una de las regiones más afectadas por la depauperación (Benassar, 1978: 133-137), -por ello se convirtió en la principal emisora de población para las Indias Occidentales (Benassar, 1978: 135))-, las cifras llegaron a ser alarmantes: Trujillo, en 1557, tenía un $45 \%$ de pobres entre los que se incluían hidalgos, bachilleres, profesionales liberales o esposas de caballeros; y Cáceres, en 1527 sufre un $25 \%$ que se multiplica hasta alcanzar el $42 \%$ en 1535 .

La importancia cuantitativa de la pobreza llegó a reflejarse en la literatura. Una de las manifestaciones más interesantes de la mendicidad fue la picaresca, así lo describe Julián de Juderías: «El prado estaba lleno de mendigos que iban de coche en coche pidiendo con chanzas y llevando recados de unos a otros, y lo mismo ocurría en todos los concursos de la gente y fiestas públicas, no habiendo bodegón y puesto de limonadas que no encontraran dos o tres pobres, como si fueran hermanitos de devoción (...) la caridad indiscreta y la piedad hipócrita y verdadera contribuían al fomento de esta plaga social, y los mendigos creían con alta razón que sus llagas fingidas y sus enfermedades postizas eran de más producto que los juros y los censos y de rendimiento más cierto y menos expuesto a contingencias que el viaje harto azaroso de los galeones del Perú». (Deleito Piñuela, 1989: 184)

Los pobres llenaban las calles, las plazas y las iglesias. Mateo Alemán dice que los pobres castellanos piden «con fueros, haciéndose malos requisitos, respondones y mal sufridos», (Deleito Piñuela, 1989: 186) como así aparece reflejado en El Guzmán de Alfarache. En general, la literatura picaresca española retrata a los pobres como altivos y or- 
gullosos, cuya circustancia pasajera no les impedía creerse personajes de gran poder y honor.

\section{EL DEBATE ¿QUÉ HACER CON LOS POBRES?}

Como ya hemos dicho antes, la consistencia de un orden justo inmerso en una economía moral (Callahan, 1980: 21) dominaba la asistencia social. Aristóteles había dicho en su obra Política que los hombres tenían una función fija. La mentalidad medieval escolástica española había construído una sociedad de ordo rectus, en la que la función de los hombres y las mujeres era una cuestión divina y no humana. Pero los terribles cambios que llegaron a España durante el siglo XVI obligaron a una importante evolución en el pensamiento social.

La llamada que hace Lutero en 1520 a la nobleza para la mejora de la condición de los pobres es esencial: «es de máxima importancia extirpar cualquier clase de mendicidad de todo el mundo cristiano. Ningún cristiano debería mendigar» (Geremek, 1989: 197). Lutero aboga por la prohibición de la mendicidad para lo cual se propone que cada ciudad mantenga a sus pobres e impida la entrada de otros. En cambio, Erasmo de Rotterdam, la mayor figura del Humanismo, propone el elogio de la saridad, para tratar a los más necesitados: «Ca donde Dios está, allí mora la caridad, pues el mesmo Dios es caridad. Porque, de otra menera, si tú eres niembro vivo de Cristo, dime ¿cómo puede alguna stra parte deste cuerpo tener dolor, sin que tú también te duelas ni aun lo sientas? ( Bataillon, 1986: 193). Para Erasmo, el amor y la educación serán los preceptos fundamentales que reflejará en el Enchiridion. Frente a Lutero, Calvino o Tomas Moro que incidirán más en el trabajo.

Estas ideas erasmistas penetran, se difunden y zalan profundamente en algunos teólogos españoles, de entre ellos sin duda el más importante para la teoría de la asistencia social será Luis Vives. $E l$ elogio de la locura (1511) y en Enchiridion serán las obras más influyentes de Erasmo, pero no sólo las obras del de Rotterdam, también Utopía (1516) le Tomas Moro que desacralizaban la pobreza y el Liber vagatorum (1526) de Lutero que la condena- ba e igualaba al pecado serán trascendentes en la controversia. Según Pedro de Burgos y Rodrigo de Luján en España «...ya se percibe contradicciones básicas para la maduración de la auténtica burguesía, ya que intereses de exportadores y fabricantes eran divergentes» (Pérez de Herrera, 1975: 84).

A pesar de la fuente inagotable de riqueza que significa América, España se resiste a desarrollar la mentalidad capitalista como estaba ocurriendo en Europa, en esta coyuntura se desarrolla el debate. Según Cavillac y Josep Pérez (Pérez de Herrera, 1975: 87) se produce una bipolarización de la sociedad española, con ausencia de una clase media y avance de la indigencia. Se trata del lento camino hacia el caos del siglo XVII.

A partir de 1523 en casi todas las cortes celebradas abundan las denuncias de la proliferación de mendigos y ladrones (Pérez de Herrera, 1975: 88). En 1525 la mendicidad sin licencia se llega a prohibir en algunas ciudades.

En este clima de indecisión ante la explosión del fenómeno aparece De subventione pauperum, de Luis Vives. Quizá se trate del primer tratado sociológico de la asistencia social.

Luis Vives piensa que es errónea la relación entre honor y dinero: «el dinero...pasó a ser el instrumento universal del honor (Pérez de Herrera, 1975: 90). «...de este modo ricos y pobres se convertirán en ladrones: unos por atesorar y otros por conseguir estar ociosos». Lo más importante es que la pobreza pasa de ser una bendición divina a una calamidad y una injusticia social (Pérez de Herrera, 1975: 92). Esto no lo había dicho nadie en toda Europa, supone una gran revolución para la teoría de la asitencia social que se hallaba en una callejón sin salida entre la inoperante piedad medieval y la divinización del trabajo que se traducía en perseguir a los mendigos. Vives propone una tercera vía para la solución del problema: la reinserción social a través de la educación. Se desplaza a la Iglesia, el Estado será el encargado de administrar colegios para los niños pobres y organizar censos para distinguir los verdaderos de los falsos pobres, además el trabajo será obligatorio para aquellos que pueden, y por úl- 


\section{8 - Cultura de los Cuidados}

timo se prohibirá la mendicidad. El proyecto de Vives es una clara síntesis entre las medidas propuestas por Erasmo, Lutero y Moro.

Su programa era en teoría la solución para tres problemas fundamentales: la asistencia a los enfermo eliminaría la propagación de enfermedades contagiosas -no podemos olvidar que los vagabundos eran agentes propagadores de pestes de una ciudad a otra-; la educación alejaría el vicio; y el trabajo obligatorio incrementría la riqueza.

En realidad, como era de esperar, las medidas de Luis Vives nunca se llegaron a aplicar, a pesar de que en 1540 se intentan poner en práctica los primeros controles de pobres en Zamora, Salamanca y Valladolid.

En 1545 Domingo de Soto, uno de los más pretigiosos teólogos españoles publica In causa pauperum deliberatione en donde defenderá que la «...libertad del mendigo era un derecho sagrado...» (Pérez de Herrera, 1975: 98) y apela a la necesidad de la caridad individual como ejercicio necesario espiritual, e introduce diferencias entre misericordia y justicia, siendo la primera un problema de conciencia y la segunda un problema político que debe de ser administrado por la Iglesía y no por el Estado. Soto atacará a los funcionarios corruptos y vagos, antes incluso que la holgazanería de los indigentes. En cambio defiende la limosna que había sido denunciada en el Enchiridion de Erasmo.

En cuanto a los pobres verdaderos o falsos, Domingo de Soto argumenta que no es suficiente el criterio de enfermedad o incapacidad física para el trabajo, pues hay otras cuestiones como el honor que lo impiden.

En ese mismo año de 1545 la postura de Soto es contestada por Juan de Robles, también llamado Juan de Medina, abad del monasterio benedictino de San Vicente. Éste publica De la reglamentación de ayudas a los pobres practicada en algunas ciudades españolas para la asistencia a los verdaderos pobres, en donde se demuestra defensor de la Cédula Real de 1540 que había intentado controlar la mendicidad dando una cédula que identificara a cada pobre. Juan de Robles, igual que Luis Vives, pretendía distinguir entre pobres verdaderos y fal- sos. En cuanto al control de la asistencia se inclina sobre el del estado laico.

A lo largo de la segunda mitad del siglo XVI la controversia continuó. Un núcleo importante de debate tiene lugar en Brujas, allí el médico de Felipe II concede la libertad para mendigar en 1562 en el tratado de Wyts de Amberes.

Leonardo de Villavicencio, predicador y agente secreto del rey prudente en Países Bajos entra también en la polémica. Constituye en paso atrás, pues rechaza las soluciones de Wyts e incluso califica de hereje a Luis Vives. Comienza una época de intolerancia ideológica, es el principio de la contrarreforma. El erasmismo, que había sido adorado empezará a ser perseguido y diabolizado, en estos años con mucho más vigor. Se intenta retroceder a la moral medieval en política asitencial, esto significa que la misericordia se antepone a la justicia social, que era la base en el proyecto de Luis Vives.

Pero la pobreza avanza rápidamente en estos años, los desequilibrios sociales eran cada vez más grande, España se precipita por un plano inclinado hacia la ruina económica. Los precios del trigo se disparan, y las manufacturas se hunden por no poder competir con las extranjeras, las bancarrotas del estado se suceden periódicamente. El empobrecimiento de la sociedad española es tan agudo que a pesar del clima de contrarreforma, se intentan resucitar algunas ideas del programa asistencial de $\mathrm{Vi}$ ves: se crea la figura del Padre de Pobres que intenta buscar trabajo a los mendigos, y se pretende resucitar la Real Cédula.

Luis Ortiz publica un memorial que analiza los problemas económicos y psicológicos de los españoles. Ortiz intentaba el cambio de la mentalidac basada en el honor del hidalgo por la asimilación d $\epsilon$ la dignidad del trabajo.

En 1565 se revisa la Real Cédula con la Nuevc orden para el recogimiento de los pobres y socorr de los verdaderos (Pérez de Herrera, 1975: 115). Li dramática realidad social obliga a tomar estas medidas de influencia erasmista. Las parroquias tendrán que hacer una relación de sus pobres incapaci. tados para el trabajo y habilitarlos para la mendici. dad con la cédula que tendría que renovarse anual. 
mente. A los cinco años tenían obligación de haber aprendido algún oficio. Los estudiantes pobres tenían que tener un permiso de su rector para poder mendigar (Pérez de Herrera, 1975: 116).

Pero España sufría un proceso de aristocratización. Este hecho explica el creciente desprecio de los españoles por el trabajo o las actividades mercantiles. El comercio se encontraba controlado por extranjeros: alemanes, genoveses o portugueses (Pérez de Herrera, 1975: 120), la mayoría judíos o judeoconversos.

Los talleres de manufacturas fueron desapareciendo de las ciudades castellanas, familias enteras de artesanos se vieron arrojados a la calle por no poder hacer frente a sus deudas. A partir de 1576 el problema se vuelve a plantear otra vez en las cortes (Pérez de Herrera, 1975: 122).

En 1579 el catalán Miguel Giginta publica Tratado de remedio de pobres. Los planteamientos de Giginta eran muy sencillos: los pobres mendigaban porque no tenían otro medio de vida, si se les facilitaba otra forma de subsistir, sólo quedarían los falsos: «...los que de aquesta comodidad no quisieran gozar, se vayan o tomen otro arbitrio de vivir.» (Pérez de Herrera, 1975: 123). Para ello proponía que en cada ciudad importante se fundara una Casa de Misericordia para alojar a los desamparados, estas casas serían subvencionadas por limosnas colectivas de los pobres, donaciones de poderosos y el mismo producto del trabajo de los alojados. El programa de Giginta también contemplaba la formación de los niños, a los que se les enseñaba a contar con el fin de animarlos al oficio de comerciantes. Estas casas serían dirigidas por autoridades municipales (Pérez de Herrera, 1975: 175). La iniciativa de Giginta cristalizará en la fundación de algunas casas en Toledo, Madrid, Granada y Barcelona.

Pero España continuaba su decadencia. Desde la derrota de la Armada Invencible había entrado en un abismo irreversible. Entre 1592 y 1600 se disparan los precios y la presión fiscal sobre los campesinos. La solución para muchos fue el abandono del campo y el comienzo de la mendicidad en la ciudad - La miseria alcanza dramáticas dimensiones en esos años (Pérez de Herrera, 1975: 138).
Ya a finales del siglo XVI, el médico Cristobal Pérez de Herrera intentará el último proyecto asistencial, publica Discurso del amparo de pobres.

La Escuela de Salamanca, había demostrado que la riqueza no residía en los metales preciosos sino en la mano de obra, es decir en la población activa: «...la hacienda del rey son los hombres, no las tierras y mucho menos el dinero...»(Pérez de Herrera, 1975: 130). Perez de Herrera recojerá esta teoría.

En este clima de crisis, depresión socioeconómica y contrarreforma, los pobres seran semillero de herejes -dirá Pérez de Herrera- por encontrarse al margen de los sacramentos y por su condición libertina y desagenada. Los pobres se irán convirtiendo en uno de los terrores dentro de la sociedad de transición al barroco (Pérez de Herrera, 1975: 140). Los marginados sociales, gitanos, extranjeros, mendigos y sobre todo moriscos serán una amenaza real.

En este clima aparece el programa de Perez de Herrrera, que había sido médico de cárceles y de hermandades benéficas. Amparo de pobres pretendía tener un alcance general para todas las ciudades importantes del reino, intentaba que los desamparados aprendieran a ser buenos cristianos a través de la educación. La administración de la asistencia correría a cargo de eclesiásticos y seglares, aunque un sacerdote sería el rector y administrador (Pérez de Herrrera, 1975: 152).

Herrera proponía un control exhaustivo y riguroso de cada uno de los pobres que pordioseaban por las calles, para ello en las ciudades más importantes, a una hora exacta y en un lugar determinado se censarían los pobres en una mesa en la que estaría un funcionario real, un médico y un clérigo, éstos levantarían acta de las características del pobre, examinarían su enfermedad o invalidez física y si procedía, le darían una autorización para seguir mendigando. Este control se tendría que hacer periódicamente. Pero Herrera también estaba preocupado del aspecto moral, sobre todo en el tema de la prostitución de las mujeres; no olvidemos el frecuente contagio del mal francés, hoy conocido como sífilis. Para lo que propone trabajos de hiladura en casas. 
Pero lo más importante era la educación de los jóvenes e incluso niños mendigos, pues una causa frecuente de depauperación era la proliferación de expósitos, que luego solían comprarse o alquilarse para pedir limosna. La orientación de esta educación era a crear ingenieros, arquitectos, comerciantes y artilleros, más que letrados o clérigos.

El origen de las subvenciones serían las fortunas sin herederos, las limosnas de caballeros al entrar en una orden o por nombramiento de alto cargo en Europa o América.

Herrera participa de la mentalidad de la época: el catolicismo: instrumentum regni (Pérez de Herrera, 175: 169). Fue un intelectual comprometido con la problemática social, vecino y amigo personal de Mateo Alemán, ambos con distintos instrumentos, el memorial y la literatura, intentaron aliviar uno de los factores económicos de la tragedia española.

Según Michel Cavillac (Pérez de Herrera, 1975: 131) Amparo de pobres supone el fin de un proceso inciado con la obra de Vives, y una síntesis del pensamiento tradicional y la Reforma. De todos modos el problema de la asistencia social seguirá tratándose por arbitristas en el siglo XVII e ilustrados en el XVIII.

\section{CONCLUSIÓN}

Hace unos cinco siglos se construía en Europa una nueva forma de entender el mundo, era el $\mathrm{Hu}$ manismo. Aquellos nuevos hombres que pensaban que sólo lo humano era el centro del universo son los impulsores de la asistencia social moderna. Para Erasmo de Rotterdam y Luis Vives, enfermos y marginados eran personas con derechos inalienables. Qunientos años más tarde, solemos perder de vista con mucha facilidad la conciencia histórica, y llegamos a creer que nuestros derechos bien son una concesión gratuita del Estado, bien existen por añadidura, -como si fuera algo caído del cielo sin más-, o incluso cometemos la torpeza de considerarnos con derecho a todo. Este estado de frivolidad e ignorancia es aprovechado por ciertos sectores de nuestra sociedad para propagar un nuevo concepto: que los derechos, y en particular el derecho a una asistencia sanitaria es una mercancía con la que se puede traficar; ésta es la base teórica que nos conduciría a la privatización de nuestros hospitales. Los humanistas vencieron en la lucha por la dignidad de mendigos, margindos y enfermos. Hoy, esa dignidad que es insaparable de la condición humana, se encuentra amenazada, por todos aquellos que pretenden crear un mundo en el que hasta la enfermedad tenga un precio. Como hubiera dicho Erasmo de Rotterdam, el derecho a la salud, no se puede comprar ni vender.

\section{BIBLIOGRAFÍA}

BATAILLON, M. (1986) Erasmo y España. Fondo de Cultura Económica. Madrid.

BENNASSAR, B. (1978) Los Españoles. Argos, Barce-! lona.

CALLAHAN, J.W. (1980) La Santa y Real Hermandad del Refugio y Piedad de Madrid. Consejo Superior de Investigaciones científicas, Madrid.

CIPOLLA, C. (1990) Historia económica de la Europa preindustrial. Alianza Universidad, Madrid.

DELEITO PIÑUELA, J. (1989) La mala vida en la España de Felipe IV. Alianza, Madrid.

DELUMEAU, J. (1989) El miedo en Occidente. Taurus, Madrid.

GALBRAITH, J. K. (1992) La sociedad opulenta. Plane-: ta-Agostini, Brcelona.

GARCÍA MERCADAL, J. (1934) Estudiantes, sopistas y? pícaros. Plutarco, Madrid.

GEREMEK, B. (1989) La piedad y la horca. Alianza Universidad, Madrid.

LEWONTIN, R. C. y otros.: (1996) Crítica del racismo, biológico. Grijalbo Mondadori, Barcelona.

MARAVALL, J.A. (1989) La cultura del barroco. Ariel, Barcelona.

MARX, K. (1952) El capital. Fondo de Cultura Económica, Bogotá.

PEREZ DE HERRERA, C. (1975) Amparo de pobres. Espasa-Calpe, Madrid.

PERRY, M. E. (1993) Ni espada rota ni mujer que trota. Crítica, Barcelona.

PIRENNE, H. (1927) Histoire de Belgique. vol. III, Bruselas.

WEBER, M. (1992) La ética protestante y el espíritu del capitalismo, Península, Barcelona. 